\title{
Simulando por meio da dinâmica de sistemas a influência dos tribunais de Contas estaduais na qualidade da gestão pública e na atração de investimentos privados*
}

\section{A system dynamic simulation of the State Account Courts impact on public management and on private investments attraction}

Márcio Carvalho'

\section{Resumo}

A utilização de simulações na análise de sistemas complexos vem ganhando espaço nas ciências sociais nos últimos anos (CARVALHO, 2005; RICHARDSON, 1991; VICENTE, 2005; ZELLNER, 1984). A grande vantagem desse instrumental em relação a outros é sua possibilidade de testar diferentes cenários que não poderiam ser replicados sem problemas de ordens legal, prática e ética.

Este artigo tem por objetivo simular o impacto das ações dos tribunais de Contas estaduais na qualidade da gestão pública e, conseqüentemente, na atração de investimentos privados para os municípios. Para tal, foi desenvolvido um modelo que simula a atuação de um Tribunal de Contas estadual em um município, e o resultado revela que o tribunal exerce um papel indireto, mas importante, na atração de investimentos. Essa constatação se dá quando o Tribunal de Contas expande suas funções de instituição fiscalizadora para uma instituição de accountability de desempenho, com ênfase na capacitação dos funcionários municipais e na busca de resultados para a gestão pública.

Palavras-chave: dinâmica de sistemas; tribunais de Contas estaduais; accountability; atração de investimentos; gestão pública.

\section{Abstract}

Over the past years, the use of simulations in social sciences is increasing (Zellner, 1984; Richardson, 1991; Carvalho, 2005; Vicente, 2005). The advantage of this tool is the possibility to test different scenarios that would not be feasible in real life. In this sense, this article has as objective to simulate the impact of Brazilian State Account Courts on public management and on the investment decision made by private companies. With that objective in mind, a system dynamics model was developed. The results of the simulation show that the State Account Courts have an indirect - but very important - role on attracting private investments for the cities. This happens when the Account Courts expand their original function into an accountability for performance role.

Key words: system dynamics; state Account courts; accountability; private investments attraction; public management.

\section{Introdução}

O objetivo deste artigo é simular o impacto das ações dos tribunais de Contas estaduais na qualidade da gestão pública e na conseqüente atração de investimentos privados para os municípios. O propósito é identificar que determinantes (ou variáveis) devem ser enfatizados nas decisões do tribunal, visando à maior eficácia dos

* 0 autor está à disposição para eventuais consultas detalhadas quanto ao método, bem como para repassar o modelo e os dados que geraram as simulações apresentadas neste artigo.

'Professor da EBAPE/FGV. Doutor e Mestre em Administração Pública pela State University of New York at Albany - SUNY/Albany (Estados Unidos). Endereço: Praia de Botafogo, 190 - sala 504 - Botafogo - Rio de Janeiro/RJ - Brasil - CEP.: 22250-900. E-mail: marcio.carvalho@fgv.br. 
investimentos públicos e melhora no ambiente geral de negócios da economia dos municípios, respeitados os devidos limites constitucionais e legais.

Dessa maneira, parte-se do princípio de que o Tribunal de Contas funciona como um instrumento minimizador dos riscos decorrentes da não-execução de investimentos públicos, mais genericamente, da não-execução do previsto no Plano Plurianual (PPA), nas leis de Diretrizes Orçamentárias (LDO) e Orçamentária Anual (LOA) e do não cumprimento das exigências definidas na Lei $n^{\circ}$ 4.320/64 e na Lei Complementar $n^{\circ}$ 101/00 Suas ações minimizam a incerteza de uma ingerência administrativa que venha a impactar as contas públicas dos municípios e dos estados. Ao atuar restringindo a possibilidade de desvios do previsto no sistema de planejamento orçamentário dos municípios e do estado, o Tribunal de Contas estadual incrementa o processo de accountability, garantindo maior transparência e responsabilidade com a coisa pública. Dessa maneira, o Tribunal de Contas assume uma posição essencial na accountability do estado, com impacto concreto e direto na decisão pública e indireto na decisão privada de investimentos no estado e nos municípios.

Este artigo está dividido em duas partes. Na primeira, é apresentada uma breve discussão sobre o papel dos tribunais de Contas. A segunda parte mostra o modelo que possibilitou as simulações - construído com base na literatura sobre tribunais de Contas e accountability -, além de entrevistas semi-estruturadas com oito representantes de grandes empresas sediadas no Rio de Janeiro e 16 gestores públicos de 15 municípios do estado. Entre as várias técnicas de simulação disponíveis, a escolhida foi a dinâmica de sistemas (do inglês system dynamics). Essa escolha se deu, justamente, pela capacidade que esse tipo de modelagem tem de trabalhar com dados qualitativos e quantitativos em cenários complexos.

\section{Os tribunais de Contas}

Segundo Mansour (2002), a história dos órgãos de controle no Brasil começou no período colonial. Na época, as instituições fiscalizadoras (juntas das Fazendas das capitanias e a Junta da Fazenda do Rio de Janeiro) ficavam subordinadas à coroa portuguesa, tendo sido substituídas mais tarde por um Erário Régio e um Conselho Fazendário. A Constituição Monárquica de 1824 apresenta o primeiro registro da intenção de se criar uma instituição superior de fiscalização, nos moldes de um Tribunal de Contas. No entanto, este só surge com a Constituição de 1891, que em seu art. 89 garantiu ao Tribunal de Contas da União (TCU) competência para examinar, revisar e julgar todas as operações relacionadas com a receita e as despesas da União. A primeira Carta republicana do país dava poderes ao TCU para liquidar essas contas, verificando sua legalidade antes da prestação de contas ao Congresso Nacional (MANSOUR, 2002).

No Brasil, os tribunais de Contas foram alçados à condição de agências de accountability, ${ }^{1}$ principalmente, a partir da Constituição Federal de 1988 e da Lei de Responsabilidade Fiscal, em vigor desde 2000. Historicamente, instituições superiores de controle financeiro tendem a concentrar sua atuação na busca por uma melhor gestão dos recursos públicos. Em todo o mundo, ainda é recente a preocupação de ampliar o escopo de atuação dos tribunais de Contas para que exerçam tarefas gerenciais de avaliação do desempenho da administração, considerando os objetivos e resultados das ações governamentais (SPECK, 2000).

A partir da Carta de 1988 e da Lei de Responsabilidade Fiscal, os tribunais de Contas brasileiros têm sido levados a ampliar sua fiscalização além da formalidade e da legalidade, avaliando a gestão e os resultados da ação governamental. Na produção acadêmica, contudo, prevalece a idéia de que essa mudança ocorre em ritmo

\footnotetext{
Oriundo da administração pública norte-americana, o termo accountability não tem tradução precisa para o português (CAMPOS, 1990). Porém, em sentido genérico, refere-se à responsabilidade que têm os agentes públicos de justificar ações específicas - ou a falta delas - perante a sociedade (BEHN, 2001). Em outras palavras, a accountability encontra-se fundamentalmente ligada à questão da responsabilidade e da transparência na administração pública. Trata-se, segundo Uhr (2001), de um princípio representado por um conjunto de práticas de controle destinadas a permitir que os cidadãos verifiquem se os agentes públicos estão, de fato, fazendo aquilo que afirmam fazer.
} 
lento. Pesquisa realizada em 24 tribunais de Contas brasileiros (incluindo o TCU, tribunais estaduais e municipais), Guerreiro e Martinez (2006), por exemplo, verificaram que 50\% deles admitem realizar apenas o controle de conformidade, ou seja, limitam-se a averiguar se os atos da administração seguem as normas que lhes são pertinentes.

Cada vez mais, os debates acadêmicos apontam a necessidade de mudar o escopo do controle exercido pelos tribunais de Contas, que deveriam incorporar o que se convencionou chamar de accountability de desempenho. Figueiredo (2002) observa que não é mais suficiente o controle da legalidade, impondo-se, agora, a necessidade de também verificar a eficácia, eficiência, economicidade e efetividade da ação governamental. Segundo o autor, "a sociedade não apenas quer saber se os recursos públicos foram geridos conforme a lei, mas, sobretudo, se foram empregados da melhor maneira possível, maximizando a relação custo-benefício e tendo por objetivo o atendimento dos seus anseios." (Ibid., p.5).

A accountability de desempenho contempla a idéia de que a apreciação de contas tem caráter muito mais amplo do que o mero conceito de contabilidade, referindo-se ao desempenho global do governo. No controle tradicional, a orientação é verificar se os procedimentos estão de acordo com as regras; no controle de desempenho, é otimizar o processamento de políticas e programas públicos. No Brasil, segundo Speck (2000), a meta básica do controle ainda é averiguar a contabilidade e a autorização orçamentária para os gastos. Nos países centrais, contudo, o debate acadêmico incorpora uma crescente preocupação com a busca por novas formas de avaliar e orientar a administração pública.

\section{Simulando a atuação dos tribunais de Contas}

\section{Metodologia}

A dinâmica de sistemas é utilizada, principalmente, para o estudo e compreensão de sistemas complexos cujas variáveis interajam entre si. Isto é, não existe um conceito direto de variável dependente e independente. Ao contrário de outros tipos de simulação - como as regressões múltiplas que partem do pressuposto que exista, na maioria das vezes, apenas uma variável dependente e que as outras variáveis são independentes entre si - na dinâmica de sistema, existe uma interação constante entre as variáveis. No meio acadêmico - especialmente nos EUA e na Europa - essa metodologia vem sendo utilizada para a modelagem de ambientes de negócios, de cadeias de produção e de sistemas sociais complexos caracterizados pela interatividade dos seus agentes (RICHARDSON, 1996; STERMAN, 2000).

Uma característica importante desse tipo de modelagem é a noção de retroatividade (feedback). A retroatividade vai se referir àquelas situações onde $\mathbf{X}$ afeta $\mathbf{Y}$ e $\mathbf{Y}$ acaba afetando $\mathbf{X}$, possivelmente, por intermédio de uma cadeia de causas e efeitos. Dessa maneira, seria errado tentar analisar o impacto de $\mathbf{X}$ em $\mathbf{Y}$, e, posteriormente, de maneira isolada, o impacto de $\mathbf{Y ~ e m ~} \mathbf{X}$, tentando desse modo avaliar como o sistema se comporta. Somente o estudo do sistema como um todo, considerando a relação de retroatividade entre $\mathbf{X}$ e $\mathbf{Y}$, poderia nos levar a uma análise correta do problema.

Antes de apresentar o modelo e as simulações propriamente ditas, é necessário levar em conta alguns princípios básicos. O primeiro é o de estoque, um acúmulo no sistema, alimentado por vazões (flows) que simultaneamente adicionam e subtraem do estoque do estoque, conforme mostra a figura 1.

Figura 1. Representação de estoque e vazões

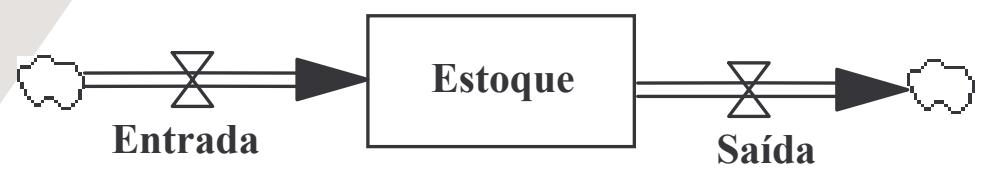


Uma vez que a vazão de entrada dos estoques é maior do que a de saída, há um acúmulo no estoque. Se o contrário acontecer, este diminuirá, podendo atingir valores negativos.

O segundo princípio básico é o de que o relacionamento entre as variáveis é demonstrado por setas que ligam essas variáveis. Dessa maneira, quando se quer afirmar que, por exemplo, as ações do Tribunal de Constas interferem na transparência da "coisa pública", essa relação é demonstrada conforme a fígura 2. O sinal positivo junto à seta quer dizer que as duas variáveis se movem na mesma direção. ${ }^{2}$ Isto é, aumentando a ação do tribunal, aumentaríamos também a transparência; diminuindo a ação, diminuiríamos também a transparência do processo.

\section{Figura 2. Relacionamento entre variáveis}

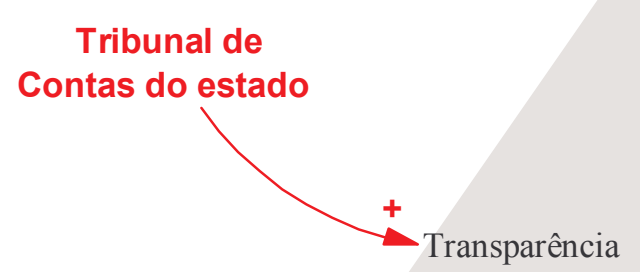

Uma terceira noção importante são os loops, base da estrutura desse tipo de modelagem. Por trabalhar com retroatividade, o sistema deve se fechar (assim como acontece na figura 4). Dessa maneira, os loops podem ser positivos ou negativos, dependendo do relacionamento entre as variáveis.

A figura 3 traz um exemplo de loop positivo na exposicão A. Quanto mais dinheiro se investe, maior vai ser o retorno do investimento, e conseqüentemente, maior vai ser o dinheiro na conta. Já na exposição B , quanto maior a população de certa região, maior será a emigração; conseqüentemente, quanto maior a emigração, menor a população dessa região.

Figura 3. Exemplos de loops

A

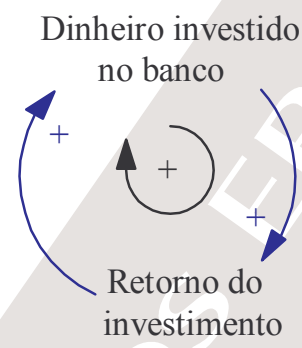

$\underline{B}$

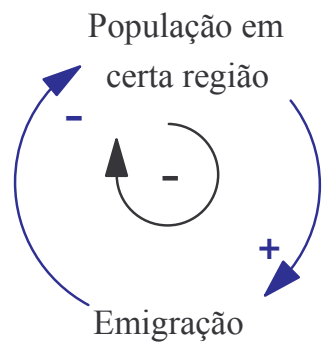

Outro princípio básico na simulação por meio da dinâmica de sistemas surge da possibilidade de se trabalhar com situações onde o relacionamento entre as variáveis não é linear, resultando em performances no tempo que também não são lineares. Esse relacionamento é demonstrado nas figuras 7 e 10.

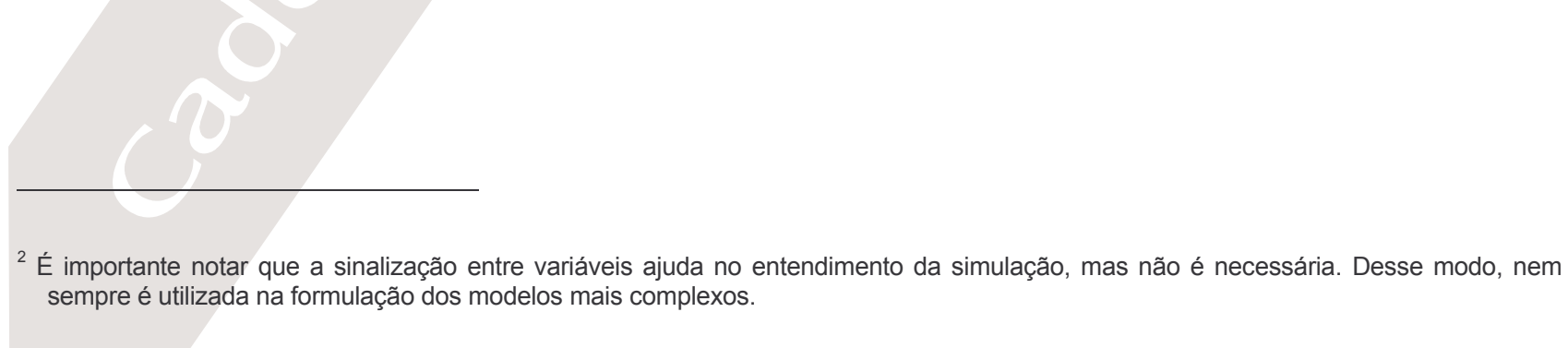




\section{Construção do modelo}

Junto com a dinâmica de sistemas, surge a conceitualização da modelagem por parte de modelos mentais. Os modelos mentais apresentam a conceitualização da idéia com o objetivo de mostrar um pouco da rede de interações dentro do sistema (RICHARDSON et al, 1994).

\section{Figura 4. Modelo mental da inserção dos tribunais de Contas}

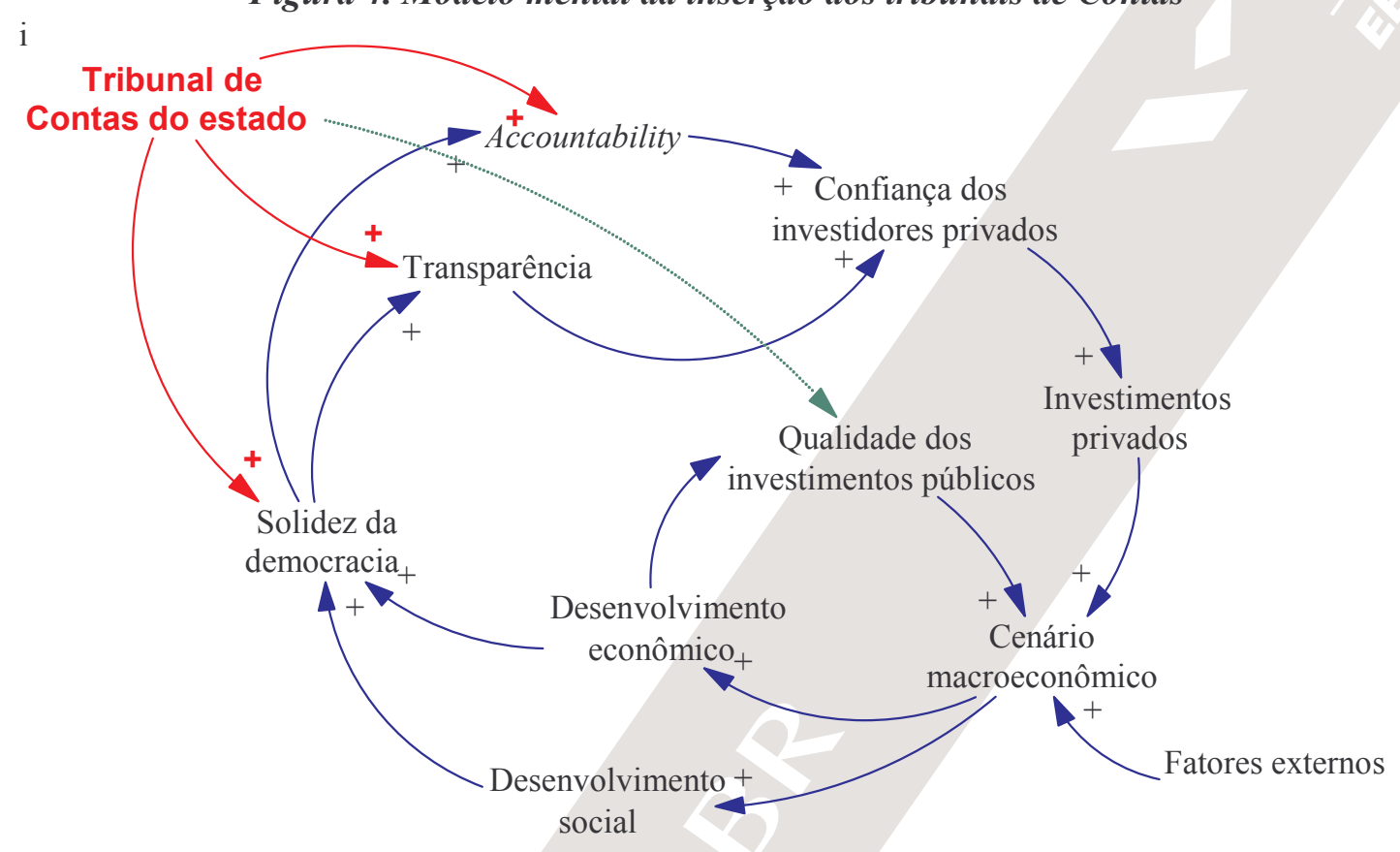

A figura 4 representa o modelo mental desenvolvido para este artigo. Essa representação retrata, de maneira simplificada e por simulação, o ambiente no qual se insere o Tribunal de Contas, bem como sua influência no investimento privado no estado. Por meio de suas ações, o Tribunal de Contas estadual possibilita maior transparência e accountability, além de consolidar a democracia, inclusive, nos municípios. Essa maior accountability e transparência tem um claro impacto na confiança da iniciativa privada, haja vista que contas públicas sanadas abrem caminho para investimentos em infra-estrutura e em outros setores, impulsionando os negócios privados. Por sua vez, novos investimentos privados impactam positivamente o cenário macroeconômico e, em conseqüência, o desenvolvimento econômico, gerando pressão por maior qualidade nos investimentos públicos. Além disso, a melhora do cenário macroeconômico também impacta positivamente o desenvolvimento social, que junto com o desenvolvimento econômico, consolida a democracia, que realimenta a accountability e a transparência, fortalecendo ainda mais o sistema.

Dessa maneira, o Tribunal de Contas do estado age - mesmo indiretamente - de duas maneiras. Primeiro, como mediador no relacionamento entre agentes (representados pelos municípios) e principais (representados pelas empresas), diminuindo o risco de investimentos em municípios que não tenham suas contas públicas sanadas. Segundo, como diminuidor da assimetria de informações entre município e empresa, haja vista que as contas municipais devem ser aprovadas pelo TCE anualmente. Essa aprovação é uma clara indicação para o mercado (signaling) de que o risco de investimento naquele município que teve aprovação pelo Tribunal de Contas é menor do que naquele município que teve as contas rejeitadas.

O modelo construído é composto de três partes principais que interagem entre si: (i) investimentos privados no município; (ii) as contas públicas do município e (iii) qualidade da gestão pública. O tempo para a simulação é de 48 meses, tendo como medida o mandato de um prefeito eleito. Assim, as ações do modelo são computadas 
mensalmente. A idéia central é modelar um determinado município. Dessa maneira, diferentes aspectos relativos ao município, sua gestão e a atuação do Tribunal de Contas estadual podem ser simulados.

\section{Investimentos privados nos municípios}

A parte relativa aos investimentos privados no município é destacada na figura 5. O estoque "investimento privado" é alimentado pelos investimentos ali realizados anualmente. Esses investimentos são frutos de uma "atração natural de investimentos para o município" - por exemplo, os municípios que ficam na costa ou perto do mar têm uma atratividade maior para o turismo, isto é, uma propensão natural para esse tipo de investimento - mais os "investimentos privados" verificados no mesmo.

A teoria econômica e as entrevistas realizadas mostraram que os investimentos privados se dão, entre outras razões, pela "percepção da estabilidade econômica do município", isto é, se os empresários percebem um bom potencial econômico naquele município, investimentos serão feitos. Essa estabilidade econômica estaria relacionada com a "qualidade da gestão pública". Se a gestão for positiva, maior será a capacidade de estabilização econômica no município e conseqüentemente, maior a atração de investimentos para o mesmo.

Conjuntamente, existe uma "fuga de investimentos". Para o modelo, essa fuga ocorre (i) por existir uma "fuga natural de investimentos", seja para outros municípios como para outros estados, e também (ii) pela "interferência da estabilidade econômica do município na fuga de investimentos"; em outras palavras, um município cuja economia não é sanada, não só não atrai investimentos, como também afugenta aquelas empresas que têm investimentos no local.

Figura 5. Visão da parte relativa aos investimentos privados em um município

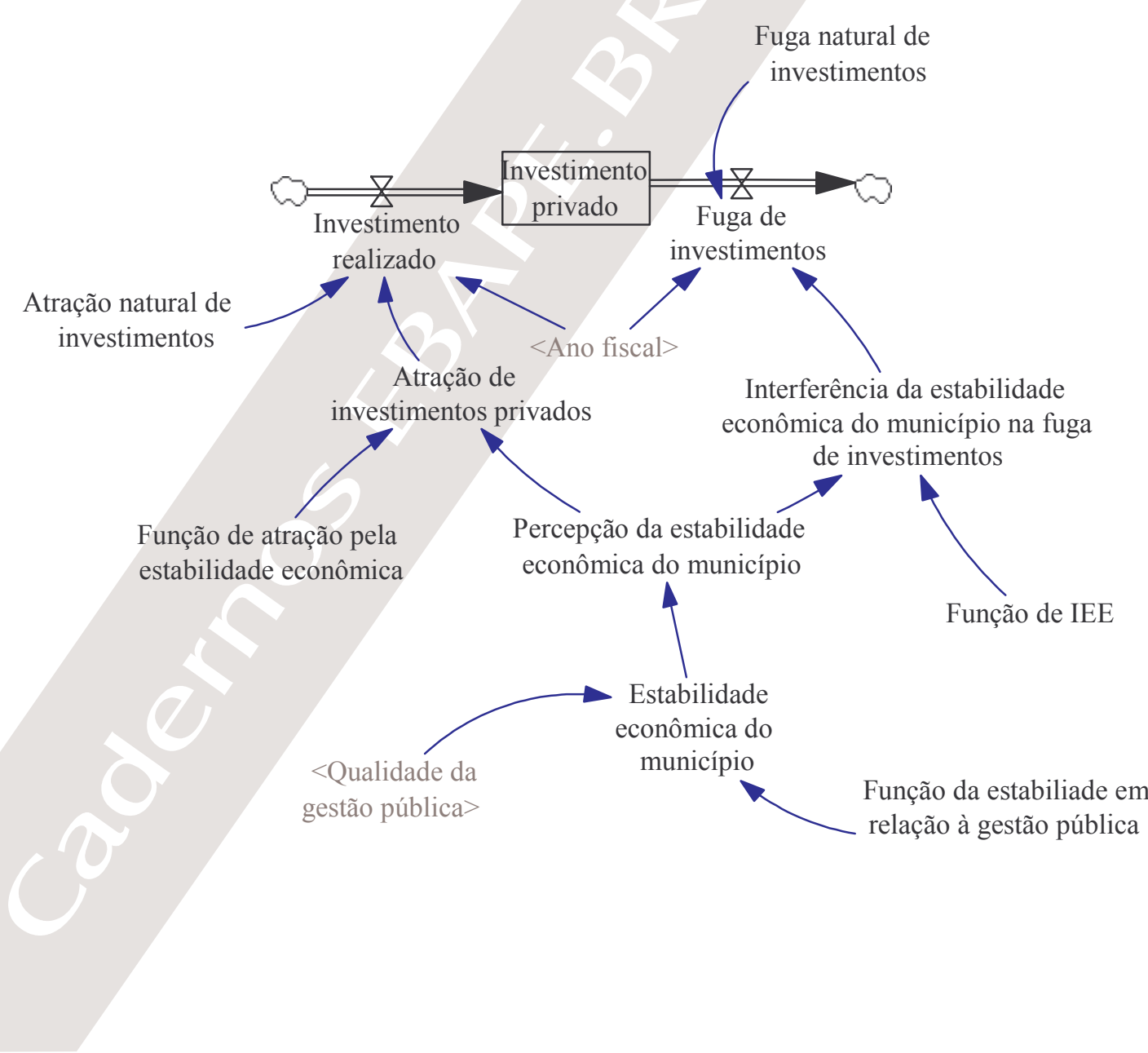




\section{Contas públicas do município}

O segundo componente do modelo são as contas públicas do município (figura 6). Existe um elemento de "arrecadação" das contas que é formado pelos recursos originados dos "impostos municipais" mais as "transferências constitucionais" que o município recebe. O objetivo, aqui, foi aproximar um pouco mais o modelo da realidade, haja vista que as transferências constitucionais compõem boa parte dos recursos municipais.

Os "impostos municipais" foram divididos em "outros impostos" (relativos a toda a arrecadação devida ao município) e em "impostos sobre investimentos privados" (os impostos e outros benefícios diretos e indiretos trazidos pela iniciativa privada para as localidades). O motivo da junção é simplificar a realidade necessária para esse tipo de modelagem

\section{Figura 6. Visão da parte relativa às contas públicas dos municípios}

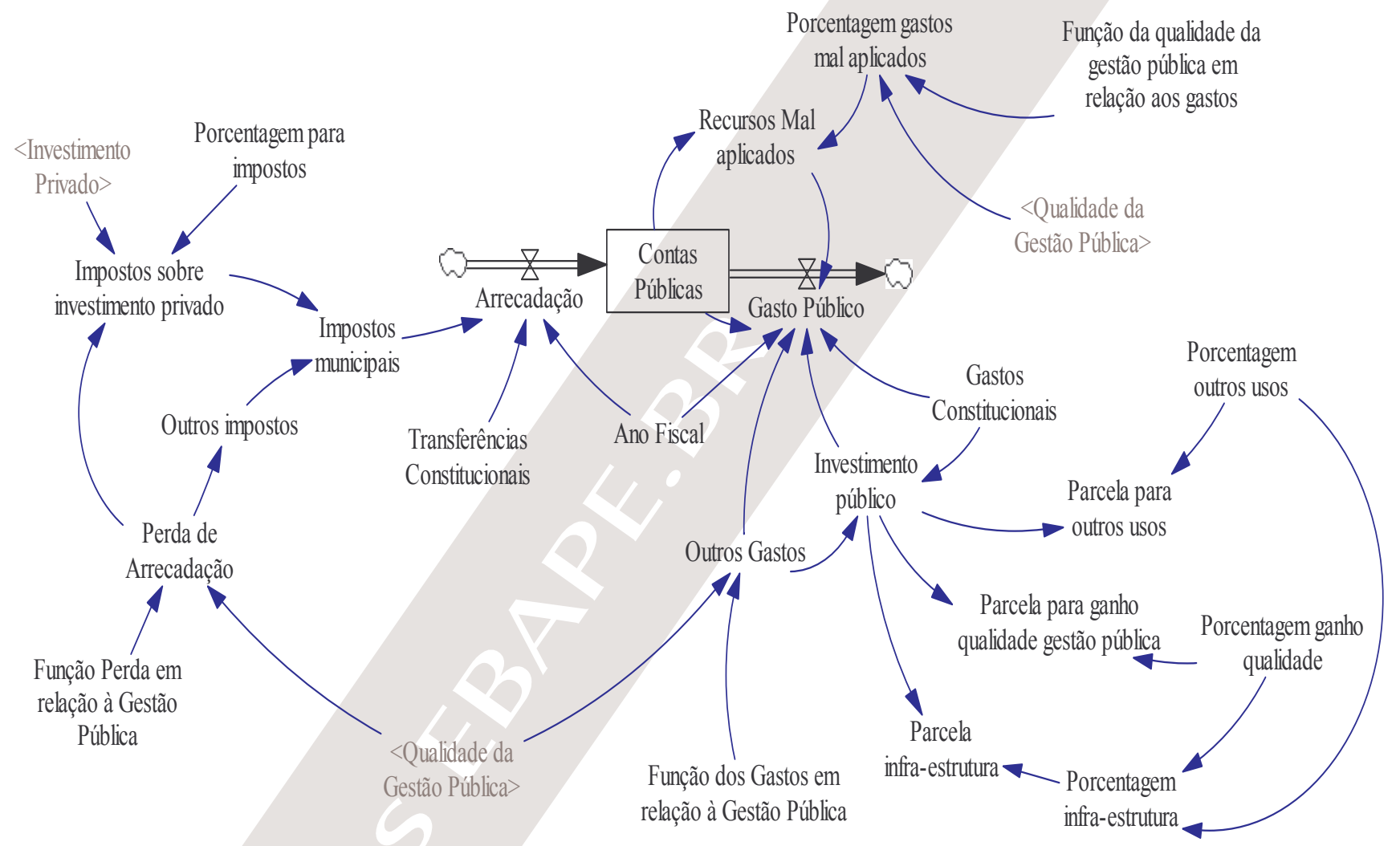

Existe uma variável que influencia os dois componentes da arrecadação ("transferências constitucionais" e "impostos municipais") que é a "perda de arrecadação", diretamente impactada pela "qualidade da gestão pública". A idéia é que se a gestão pública de um município for boa, diminui a perda de arrecadação.

A figura 7 traz a representação gráfica da relação entre essas duas variáveis. Quando a "qualidade da gestão pública" for igual a zero, existe uma "perda de arrecadação" da ordem de 95\%. Da mesma maneira, quando a qualidade for igual a 1, existe uma "perda de arrecadação" de 10\%. A idéia por trás desses números é a de que sempre há uma perda de arrecadação do município e que essa perda não está sob controle do gestor municipal. 
Figura 7. Função da perda de arrecadação em relação à gestão pública

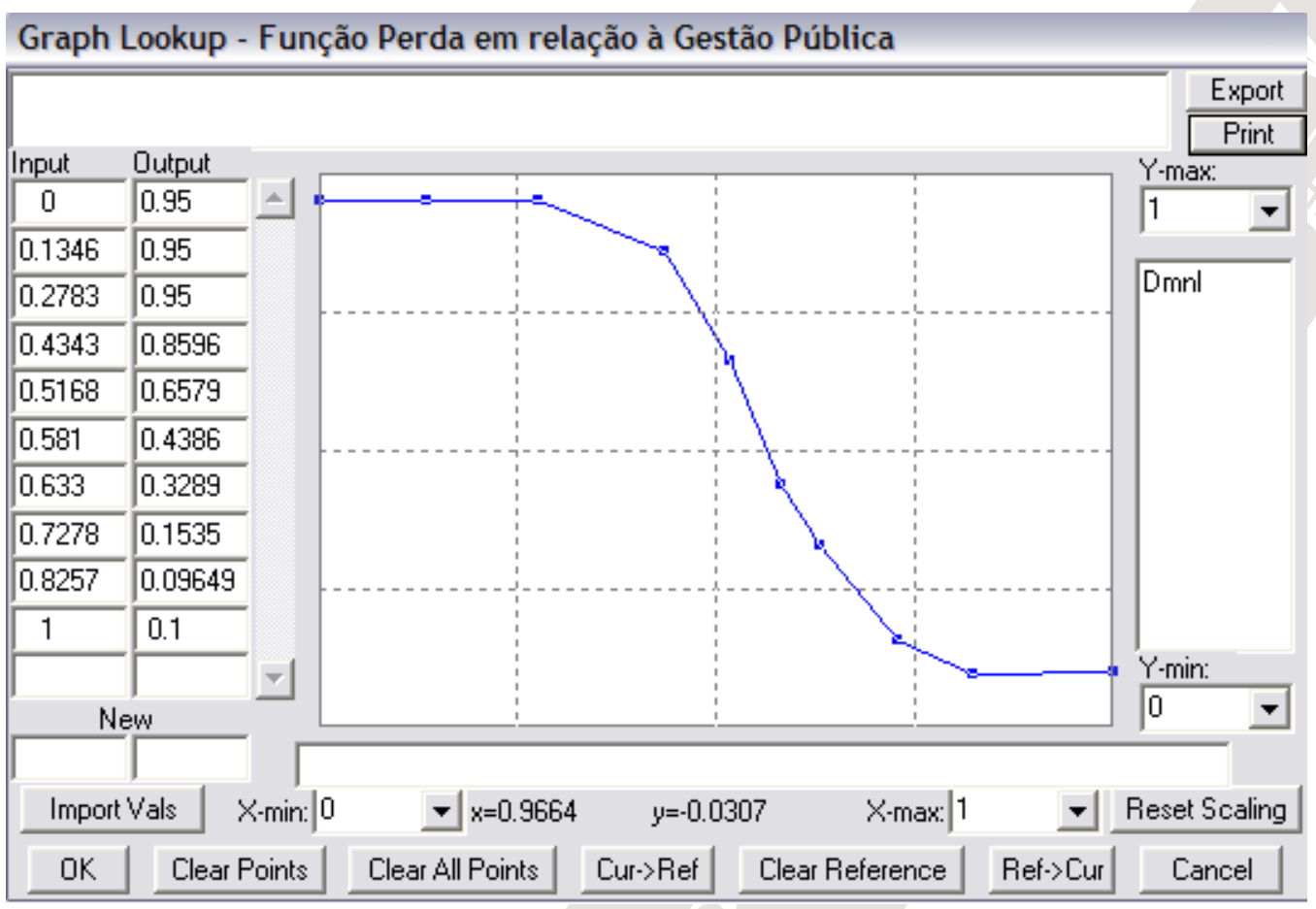

Em relação ao "gasto público" (lado direito do diagrama representado na figura 6), este é composto por três elementos:

- pelos "gastos constitucionais" - aplicações que o município constitucionalmente deve realizar;

- pelo "investimento público" - que seria aquele recurso disponível para melhorias no município; e

- por "outros gastos" - que representariam os custos fixos do município com pessoal, previdência etc.

A relação dessas variáveis foi construída da seguinte maneira:

Investimento público $=1$ - gastos constitucionais - outros gastos

Isso quer dizer que as três variáveis são responsáveis por 100\% dos gastos públicos. No entanto, primeiro de tudo, os recursos são investidos nos "gastos constitucionais", depois, nos "outros gastos", e os recursos que sobrarem são utilizados como "investimentos públicos". De acordo com o modelo, os "investimentos públicos" são utilizados de três maneiras:

- "parcela da infra-estrutura" - representando investimentos nas vias, iluminação etc.;

- "parcela para ganho da qualidade da gestão pública" - representando investimentos que o município pode fazer para melhorar sua qualidade administrativa (capacitação de pessoal, novos computadores etc.); e

- "parcela para outros usos" - que seria o uso desses recursos não necessariamente para investimentos de melhoria no município.

Uma quarta variável que acaba por influenciar os gastos públicos foi chamada de "recursos mal aplicados", que tentam representar aqueles recursos desviados por atos ilegais ou que foram utilizados fora da programação financeira do município. Essa variável também é influenciada pela "qualidade da gestão pública", e a lógica 
utilizada é a de que quanto maior for essa qualidade, menor será o impacto dos "recursos mal aplicados" nas contas públicas municipais.

\section{Qualidade da gestão pública}

A mensuração de qualidade é sempre um desafio em qualquer tipo de modelagem (Trost, 2002). Dessa maneira, a opção foi considerar a "qualidade da gestão pública" de um município como um estoque, já que a mesma pode aumentar e/ou diminuir de acordo com o tipo de política que a prefeitura municipal adotar (figura 8).

Figura 8. Qualidade da gestão pública como um estoque

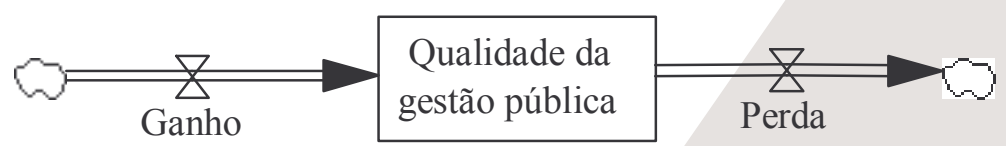

Desse modo, o "ganho" de qualidade na gestão pública envolve três fatores que o influenciam de maneira direta: (i) "influência política", (ii) "transparência e accountability" e (iii) "qualidade dos serviços". A "influência política" se verifica em função da "estabilidade política" no município. O princípio é o de que aquelas localidades com maior estabilidade terão um ganho na gestão pública, pois não ocorrem grandes rupturas na administração local. A variável "estabilidade política" pode ser escalonada de 0 a 1 , sendo 1 atribuído àquele município totalmente estável politicamente.

Figura 9. Visão da parte relativa à qualidade da gestão pública

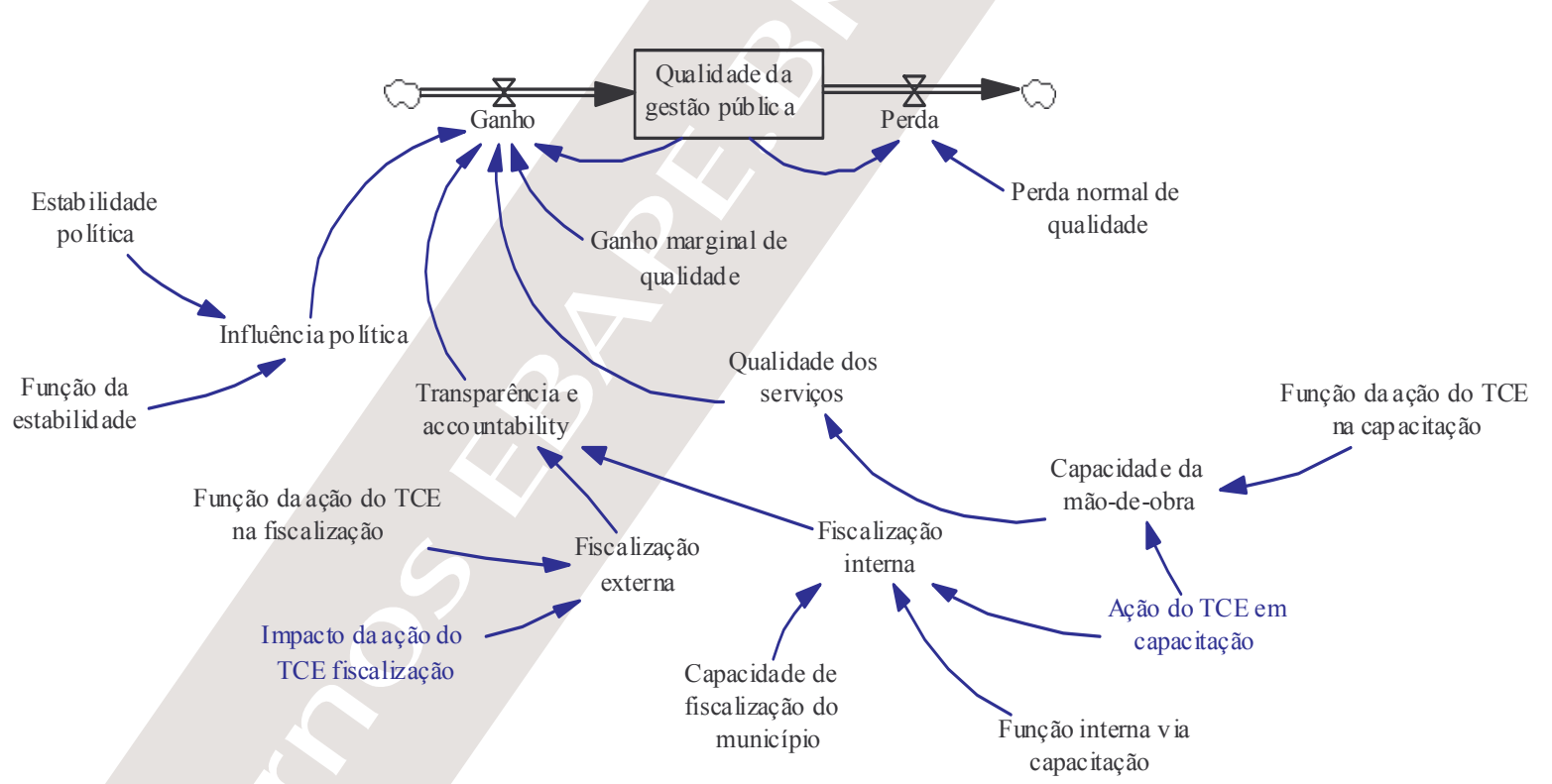

A segunda variável que se soma ao ganho de qualidade da gestão pública é a "transparência e accountability" das contas municipais. O princípio é o mesmo da variável anterior: quanto maior a transparência e accountability, maior será o ganho na qualidade. O modelo tentou seguir a percepção dos gestores públicos; assim, a "transparência e accountability" será a junção da capacidade de "físcalização interna" do próprio município com a "físcalização externa das contas do município". Em termos matemáticos: 
Transparência e accountability

$=\frac{\text { Fiscalização interna } \quad+\quad \text { Fiscalização externa }}{2}$

Nessa ótica, a "fiscalização externa" se verifica em função do "impacto da ação do TCE na fiscalização" das contas municipais. Nas simulações, as ações do TCE na fiscalização do município variam de 0 a 1 . É atribuído zero ao município que não sofreu nenhum tipo de fiscalização do tribunal e 1 ao que teve todas as suas contas escrutinadas pelo TCE. Desse modo, quanto maior a ação fiscalizadora do TCE, maior será o impacto da fiscalização externa. No entanto, a simulação não admite uma relação linear (figura 10) entre as ações de fiscalização do tribunal e seu impacto na fiscalização externa, por acreditar que exista um limite ${ }^{3}$ nas ações do Tribunal em relação aos municípios fiscalizados.

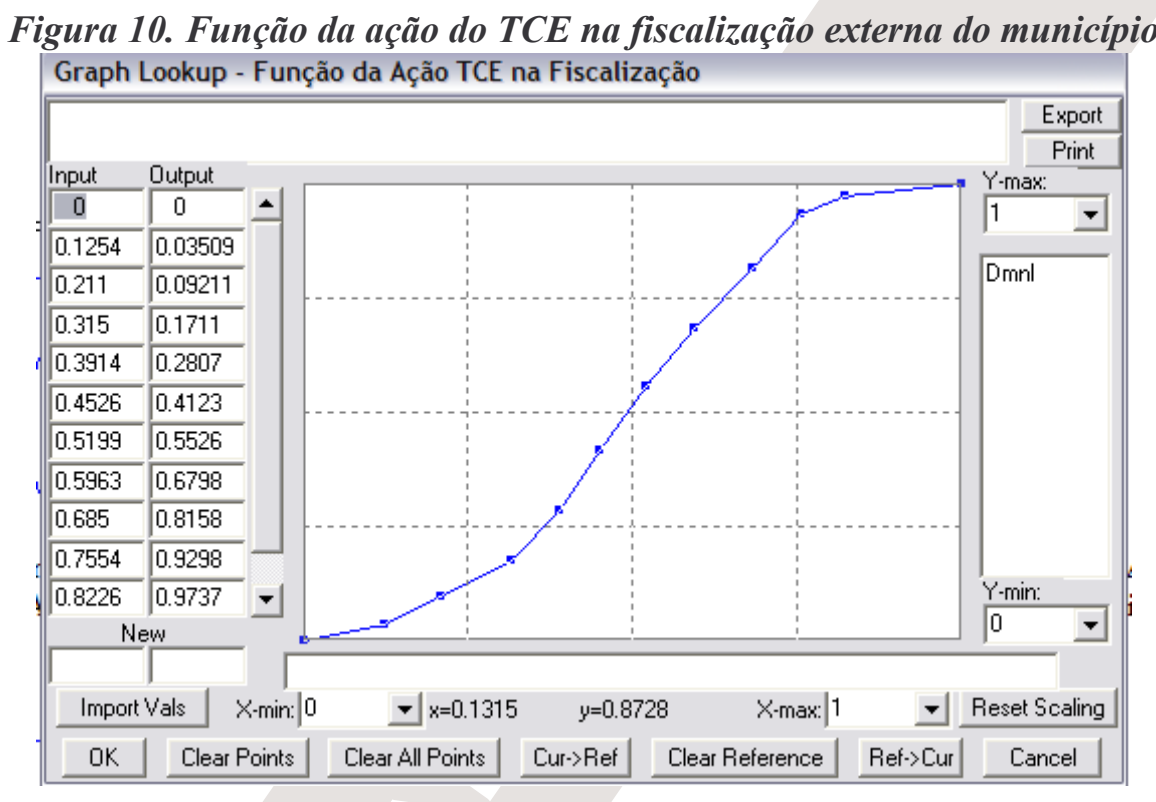

O segundo elemento que influi na "transparência e accountability no município é a "fiscalização interna" do próprio município, a qual decorre de duas outras variáveis:

- "capacidade de fiscalização do município" - isto é, se o município possui uma estrutura capaz de desenvolver esse tipo de atividade. Essa variável tem também valores que podem ser escalonados de zero a 1, atribuindo-se zero àquele município sem nenhuma capacidade de fiscalização interna e 1 ao que atende a todos os requisitos necessários ao exercício dessa função;

- influência da "ação do TCE na capacitação" das pessoas que trabalham com a "fiscalização interna". Nesse caso, essa variável é afetada pela "ação do TCE em capacitação". Essa ação varia de zero a 1, aplicando-se zero àquele município que não tenha funcionário algum capacitado pelo TCE e 1 para o que garanta a capacitação de todo o seu quadro. Quanto maior a "ação do TCE em capacitação", melhor preparados os funcionários que trabalham na fiscalização e, conseqüentemente, melhor a fiscalização do município como um todo, aumentando a accountability, e garantida a maior "qualidade da gestão pública".

\footnotetext{
${ }^{3}$ Como, por exemplo, os limites relacionados à capacidade de estrutura do município, à capacidade de pessoal do tribunal etc.
} 
A "ação do TCE em capacitação" também influencia a (iii) "capacidade da mão-de-obra" do município como um todo, o que impacta na "qualidade dos serviços" e também na "qualidade da gestão pública". Ademais, existe um "ganho marginal de qualidade" que tem como premissa que uma administração que tenha boas condições acaba por gerar por si só uma qualidade maior.

Finalmente, o modelo assume que exista uma "perda" de "qualidade da gestão pública", a qual se convencionou chamar na simulação de "perda normal de qualidade". Essa "perda" pode ser entendida de duas maneiras: primeiro, como a saída de pessoas capacitadas ou depreciação de materiais, que levam a um provável impacto nos trabalhos e, conseqüentemente, a uma diminuição da qualidade. A segunda interpretação poderia ser a de diminuição da qualidade devido a um aumento da expectativa dos clientes dos serviços. Como o serviço atingiu um patamar $X$, espera-se que daquele momento em diante os serviços sejam melhores que $X$. Assim, mesmo bem prestado, caso um serviço não atinja o patamar estabelecido, vai ser considerado ruim. Essa dinâmica pode ser interpretada como perda da qualidade.

\section{Simulações}

O objetivo por trás das simulações é mostrar o encadeamento de resultados e impactos entre os três grandes estoques do sistema montado: o "investimento privado no município", as "contas públicas" e a qualidade da gestão pública (figura 11). Para tal, foram realizadas três simulações utilizando o modelo construído.

\section{Figura 11. Encadeamento dos estoques da simulação}

Com o objetivo de possibilitar a comparação entre as três simulações, apenas cinco variáveis do modelo tiveram seus valores modificados. As variáveis e os valores assumidos para as mesmas são apresentados na tabela 1 . 
Tabela 1. Valores das variáveis para as três simulações

\begin{tabular}{lccc}
\hline \multicolumn{1}{c}{ Variável } & Simulação 1 & Simulação 2 & Simulação 3 \\
\hline $\begin{array}{l}\text { Atração natural de } \\
\text { investimentos privados }\end{array}$ & $2^{\mathrm{i}}$ & 2 & 2 \\
\hline $\begin{array}{l}\text { Ação do TCE na } \\
\text { fiscalização }\end{array}$ & $0,5^{\mathrm{ii}}$ & 0,5 & $0,65^{\mathrm{iii}}$ \\
\hline $\begin{array}{l}\text { Ação do TCE na } \\
\text { capacitação }\end{array}$ & $0,2^{\mathrm{iv}}$ & $0,65^{\mathrm{v}}$ & 0,65 \\
\hline Estabilidade política & $0,5^{\mathrm{vi}}$ & 0,5 & 0,5 \\
\hline $\begin{array}{l}\text { Capacidade de } \\
\text { fiscalização do } \\
\text { município }\end{array}$ & $0,2^{\mathrm{vii}}$ & 0,2 & $0,5^{\mathrm{viii}}$ \\
\hline
\end{tabular}

\section{Observações sobre a tabela 1:}

i) numa escala de 0 a 10, representa um município com pouca atratividade para os investimentos privados;

ii) numa escala de 0 a 1, representa um município com uma atuação normal do Tribunal de Contas;

iii) numa escala de 0 a 1, representa um município ao qual o TCE dispensou uma maior atenção na fiscalização - representa um município que passou por uma fiscalização do TCE mais rigorosa;

iv) numa escala de 0 a 1 , mostra um município com baixa capacitação de pessoal pelo TCE;

v) numa escala de 0 a 1, mostra uma capacitação de pessoal acima da média;

vi) numa escala de 0 a 1 , representa um município estável politicamente, mas sujeito a rupturas no processo e, conseqüentemente, na administração pública;

vii) numa escala de 0 a 1, mostra um município com baixa capacidade de fiscalização interna das suas contas; e

viii) numa escala de 0 a 1 , indica um município com uma capacidade mediana de fiscalização interna de suas contas.

Em resumo, a primeira simulação levou em consideração um município pequeno que tenha uma capacidade baixa de atração de investimentos privados e uma baixa capacidade de fiscalização interna, em conjunção com o que poderíamos considerar uma ação moderada de fiscalização do TCE. Ademais, esse município teria poucos funcionários públicos treinados pelo tribunal. Na segunda simulação os valores de todas as variáveis do sistema foram mantidos, com exceção da "ação do TCE para capacitação" de funcionários. O objetivo foi testar o impacto de uma melhora de 0,2 para 0,65 ; o que seria o mesmo que dizer que $65 \%$ dos funcionários da prefeitura foram capacitados pelo Tribunal de Contas do estado. Na terceira simulação são mantidos os valores da simulação 2, acrescendo uma maior fiscalização por parte do Tribunal de Contas, bem como uma maior capacidade de fiscalização do município simulado. 


\section{Resultado das simulações ${ }^{4}$}

A primeira observação que se faz pertinente acontece em relação à "qualidade da gestão pública". A figura 12 compara o mesmo município nos três cenários descritos anteriormente. A linha verde - representando a primeira simulação - mostra a tendência natural de que essa qualidade diminua ao longo do tempo se não houver algum tipo de intervenção. A linha vermelha - representando a segunda simulação - mostra um incremento da qualidade da gestão pública devido à capacitação do quadro de funcionários municipais por meio da ação do Tribunal de Contas do estado. Por último, a linha azul representa o cenário onde, além da capacitação, acontece também um aumento da fiscalização por parte do tribunal. Dessa maneira, se nada for feito, existe uma tendência natural de que a qualidade da gestão pública no município piore. $\mathrm{O}$ advento da capacitação de pessoal e fiscalização força um aumento dessa qualidade da gestão.

Figura 12. Qualidade da gestão pública

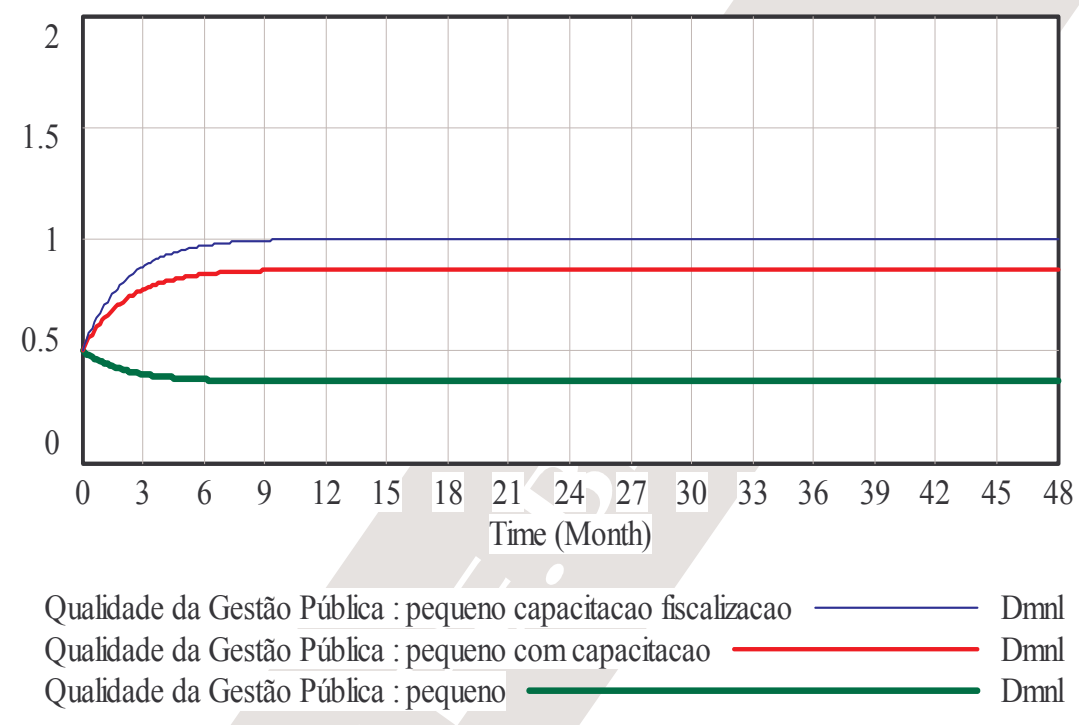

A qualidade da gestão pública impacta na "estabilidade econômica do município" e, conseqüentemente, na "atração de investimentos privados" (figura 13). É importante notar que, pela simulação, a atração de investimentos privados tem um grande ganho entre a situação original - simulação 1 (linha verde) - e a situação onde há a capacitação do quadro de funcionários - simulação 2 (linha vermelha). No entanto, o ganho com o aumento da fiscalização - simulação 3 (linha azul) - em relação à segunda simulação não é tão expressivo. Graficamente, as duas linhas acabam, na prática, sobrepondo-se.

O ideal seria apresentar separadamente o resultado de cada simulação. No entanto, para maior fluência do texto, as três simulações serão mostradas de modo comparativo. 
Figura 13. Atração de investimentos privados

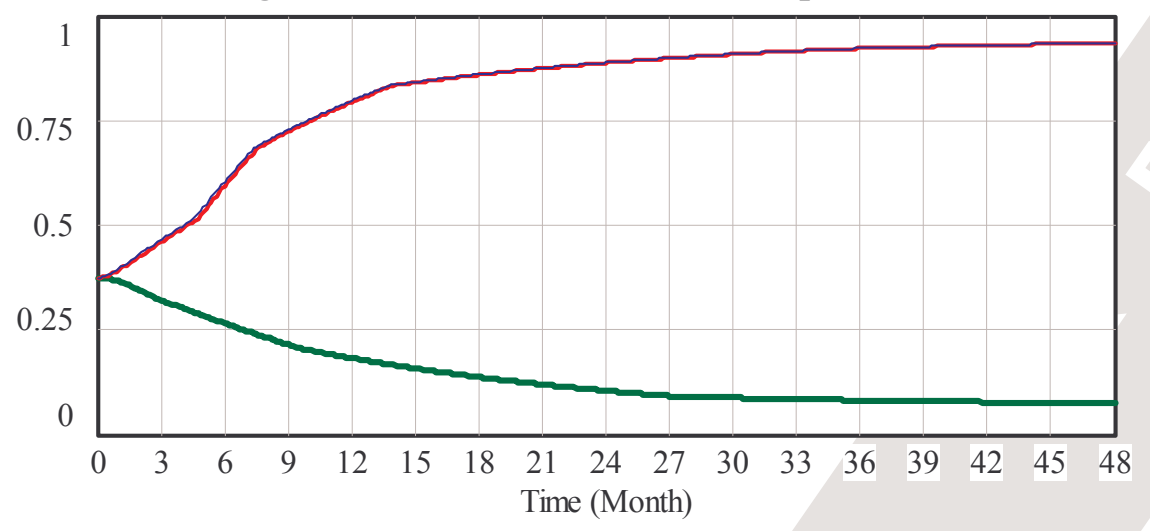

Atração de investimentos privados : pequeno capacitacao fiscalizacao —— Dmnl

Atração de investimentos privados : pequeno com capacitacao — Dmnl

Atração de investimentos privados : pequeno

O mesmo comportamento é notado também nas "contas públicas do município" (figura 14). Na situação original (linha verde), o município acaba por ter um ganho e, posteriormente, uma perda dos recursos. Com a capacitação (linha vermelha) e com a capacitação mais fiscalização (linha azul) há um incremento considerável das contas públicas. Novamente, o ganho das contas públicas do segundo para o terceiro cenário é pequeno.

Figura 14. Contas públicas do município

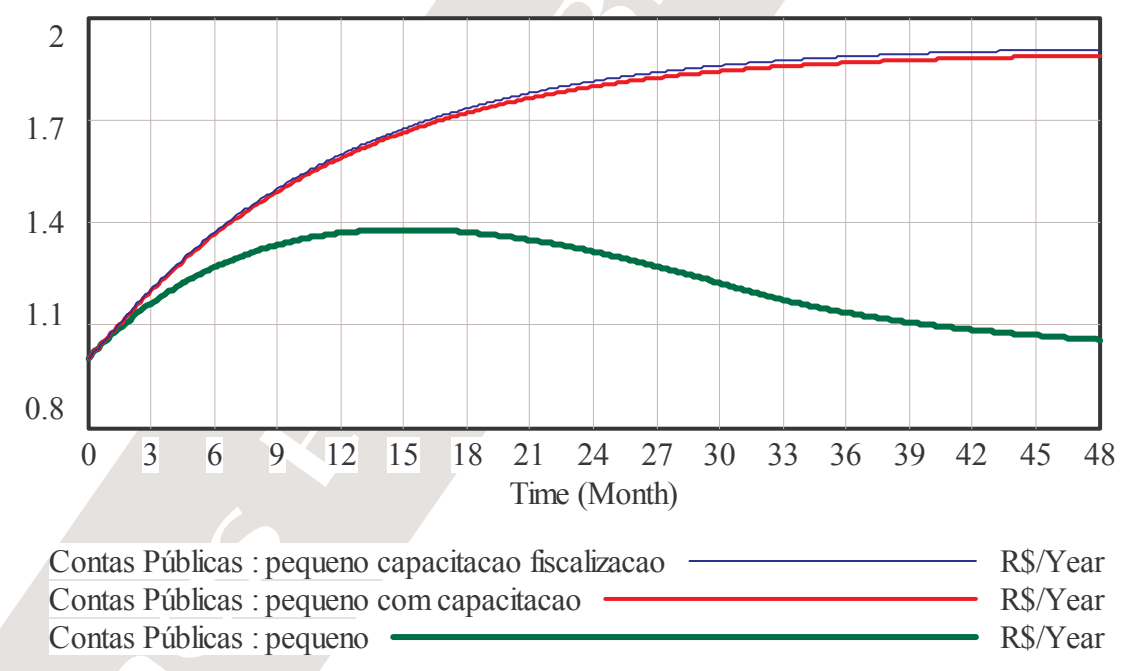

\section{Observações finais}

Os Tribunais de Contas no Brasil representam uma grande evolução na manutenção e aprimoramento da República. Desde sua concepção, essas instituições vêm avançando nas suas funções, que evoluíram da auditoria das contas públicas para funções mais ligadas à accountability, isto é, de auxílio aos entes federados por uma maior responsabilidade e transparência na administração pública.

Nesse sentido, o objetivo deste artigo foi simular os resultados das ações dos tribunais de Contas estaduais pela qualidade da gestão pública e pela atração de investimentos privados para os municípios. É importante salientar 
que o modelo desenvolvido é apenas uma representação simplista da realidade, e que devido a essa característica, utiliza uma série de preceitos e suposições retiradas das entrevistas e das teorias econômicas e sociais. Dessa maneira, a ausência de algumas variáveis pode ser contestada, bem como algumas vinculações que haja entre elas. Ademais, o modelo aqui apresentado não é uma obra totalmente acabada, haja vista que a simulação pode ser expandida a níveis maiores de complexidade. No entanto, as entrevistas feitas e a literatura que trata do assunto validam o modelo, refletindo de maneira relativamente adequada as relações entre um Tribunal de Contas estadual e os municípios, no que tange à qualidade da gestão pública e aos investimentos nesses municípios. Vale salientar que o objetivo da simulação não é prever possíveis cenários, mas entender como as ações de fiscalização e de capacitação de mão-de-obra dos municípios por parte de um Tribunal de Contas impactam na qualidade da gestão pública e na atração de investimentos privados.

Assim, com base em três simulações de um município de pequeno porte, sem muitos atrativos para as empresas privadas, notou-se que a não-ação do Tribunal de Contas do estado leva a uma perda da qualidade da gestão pública. Conseqüentemente, há uma diminuição da atratividade do município, seja para empresas privadas como para os próprios moradores.

A partir do momento em que é adotada uma ação mais efetiva do Tribunal de Contas na capacitação da mãode-obra das administrações municipais, o modelo se comporta de maneira diferente, mostrando maior qualidade da gestão pública e em relação a outras variáveis, principalmente, no que diz respeito à atração de investimentos privados. No entanto, o mesmo grau de acréscimo ao modelo não foi constatado quando se manteve a capacitação e aumentou-se o componente de fiscalização do tribunal. Esse fato leva à dedução de que o ganho para a gestão pública municipal é maior quando ocorre a capacitação de seus funcionários, do que quando se exerce apenas uma fiscalização mais rigorosa das contas públicas. Ademais, a capacitação acaba por ter um impacto maior na gestão municipal, pois gera conhecimento que é acumulado pela administração pública local, fazendo com que no futuro a ação punitiva via fiscalização seja reduzida, uma vez que os municípios estarão em conformidade com as regras estabelecidas pelo tribunal.

Dessa maneira, a mudança de enfoque da fiscalização para a capacitação como instrumento de ação, faz com que os tribunais de Contas dos estados se aproximem do que a literatura designa accountability de desempenho. Isto é, o foco passa a ser a verificação se as ações produzem os resultados esperados e se estes se mostram em evolução quando comparados com aqueles obtidos no passado. A filosofia desse tipo de accountability é a de que o governo não deve apenas usar o dinheiro de forma prudente e tratar a todos de maneira igual, mas, também, esforçar-se para alcançar o propósito público. A preocupação primordial é com a qualidade e a conseqüência das suas ações, e também com a gestão pública. Na accountability de desempenho, parte-se do princípio de que os órgãos de controle incorporam ações preventivas, ou seja, saem das ações ex post para ações ex ante (BEHN, 2001; FIGUEIREDO, 2002). No caso dos tribunais de Contas estaduais, isso funcionaria pela capacitação da mão-de-obra municipal e pelo atendimento às solicitações dos gestores públicos municipais e pelo esclarecimento das dúvidas levantadas pelos gestores públicos municipais.

Com uma maior atuação dos tribunais de Contas estaduais buscando a accountability de desempenho, há uma melhora da capacidade administrativa do município através de uma gestão mais eficiente da coisa pública. Isso proporciona maior estabilidade política e econômica, tornando o município mais atraente para a iniciativa privada. Assim, a contribuição direta dos tribunais de Contas para a gestão pública acaba impactando indiretamente na atração de investimentos privados. 
Simulando por meio da dinâmica de sistemas a influência dos

\section{Referências}

BEHN, Robert D. Rethinking democratic accountability. Washington, DC: The Brookings Institution, 2001.

CAMPOS, Anna Maria. Accountability: quando podemos traduzi-la para o português? Revista de Administração Pública, v.24, n.2, p.3050, 1990.

CARVALHO, Márcio A. 0 uso da teoria do julgamento social no estudo de políticas públicas. Cadernos Ebape.BR, v.III, n.2, p.1-18, jul. 2005. Disponivel em: <http://www.ebape.fgv.br/cadernosebape>.

FIGUEIREDO, Carlos M. C. Ética na gestão pública: o papel dos tribunais de Contas brasileiros como agências de accountability. 0 caso do Tribunal de Contas de Pernambuco. In: CONGRESSO INTERNACIONAL DEL CLAD SOBRE LA REFORMA DEL ESTADO Y DE LA ADMINISTRACIÓN PÚBLICA, VII, Lisboa, Portugal, 2002. Anais. Lisboa.

GUERREIRO, Cristina Maria Cunha; MARTINEZ, Antônio Lopo. A ação dos tribunais de Contas brasileiros para o controle dos recursos públicos. In: ENCONTRO DA ASSOCIAÇÃO NACIONAL DE PÓS-GRADUAÇÃO E PESOUISA EM ADMINISTRAÇÃO (ENANPAD), 30., 2006, Salvador. Anais. Salvador

MANSOUR, Tatiana Rebello. Tribunal de Contas do Estado do Acre: considerações sobre eficiência e eficácia do controle externo. 150p. (Dissertação de Mestrado) - Escola de Administração de Empresas de São Paulo (Easp), Fundação Getulio Vargas (FGV), São Paulo, 2002.

RICHARDSON, George P. Feedback thought in social science and systems theory. Philadelphia: University of Pennsylvania Press. 1991. $374 \mathrm{p}$.

System dynamics: simulation for policy analysis from a feedback perspective. In: (Ed.). Modelling for management I: simulation in support of systems thinking. Brookfield, USA: Dartmouth Publishing Company, 1996. v.1.

et al. Foundations of mental model research. In: 1994 INTERNATIONAL SYSTEM DYNAMICS CONFERENCE, July 11-15, 1994, Stirling, Anais...Scotland.

SPECK, Bruno Wilhelm. Inovação e rotina no Tribunal de Contas da União: o papel da instituição superior de controle financeiro no sistema político-administrativo do Brasil. São Paulo: Fundação Konrad Adenauer. 2000

STERMAN, John D. Business dynamics: systems thinking and modeling for a complex world. New York: Irwin McGraw-Hill, 2000.

TROST, Christopher. A dynamic model of work quality in a government oversight organization. System Dynamics Review, v.18, n.4, p.473495, 2002.

UHR, John. Accountability, scrutiny and oversight. Background paper prepared for the Common Wealth Secretariat, Canberra Meeting, Canberra, Australia, 2001; Australian National University. Disponivel em:

$<$ http://www.cdi.anu.edu.au/research_publications/research_downloads/JohnUhr.pdf>. Acesso em: nov. 2002.

VICENTE, Paulo. 0 uso de simulação como metodologia de pesquisa em ciências sociais. Cadernos Ebape.BR, v.III, n.1, p.1-9, mar. 2005. Disponivel em: <http://www.ebape.fgv.br/cadernosebape>.

ZELLNER, Arnold. Perspectives on mathematical models in the social sciences. In: (Ed.). Basic issues in econometrics. Chicago: University of Chicago Press, 1984. (Perspectives on Mathematical Models in the Social Sciences, p.xxi, 334). 